\title{
Opinião
}

\section{As organizações e a Escola de Minas de Ouro Preto}

\author{
Orlando Euler de Castro
}

\section{As organizações - tendências}

Uma organização é qualquer agrupamento de pessoas com o objetivo de atender às necessidades de outras pessoas. Ela compreende instalações, equipamentos (Hard), tecnologia, procedimentos, métodos (soft) e as próprias pessoas, que usam insumos obtidos na sociedade e os transformam em produtos (bens e serviços) oferecidos à sociedade. Sua sobrevivência é garantida enquanto consegue a satisfação de todas as pessoas envolvidas: clientes, dono ou acionistas, funcionários e comunidade.

Nesse mundo de globalização controvertida e crescente, em que se tornam cada vez mais ágeis as transformações tecnológicas, comerciais e corporativas, fica cada vez mais reduzido o tempo de incorporação de inovações à realidade dos negócios. Assim a capacidade para realizar ou liderar mudanças será essencial para garantir a sobrevivência.

Nesse cenário, atual e futuro, serão vencedores aqueles preparados para tais mudanças.

A mudança das organizações pressupõe mudança prévia das pessoas que dela participam. E as maiores dificuldades não se encontram nos recursos materiais e tecnológicos; estão em nossas mentes, implicando revisão ou abandono de paradigmas.

Antecipar-se pressupõe desprendimento e preparo para o novo; pressupõe humildade; dar espaço e ouvido aos questionadores e contestadores; disposição para mudar mesmo quando se ima- gina ter sucesso; estimular a criatividade e a inovação.

A acomodação, o marasmo e a imobilidade podem caracterizar perda de espaço, o que pode propiciar que a organização seja ultrapassada e que possa mesmo regredir.

Assim, possuir cultura da mudança significa:

- Ter cultura institucional de pros-pecção, para identificar tendências no ambiente externo e projetar cenários; avaliar internamente, com isenção, forças e fraquezas; rever valores e possuir visão para perceber onde se pode chegar; rever processos; estabelecer metas; estabelecer e rever estratégias; fazer análise organizacional e rever estrutura.

- Colocar a organização e o atendimento à sociedade (benefício) à frente das vaidades e aspirações individuais.

- Descentralizar, assegurando que as mudanças ocorram em todas as áreas da organização e sejam realizadas por todas as pessoas. "As organizações não podem mais ser conduzidas por apenas um ou dois heróis".

É indispensável que a velocidade de mudanças internas não seja inferior à de mudanças externas.

As organizações competitivas preci-sarão, permanentemente, manter todas as pessoas que nela atuam bem informadas, assegurar bom ambiente de trabalho, promover o trabalho em equipe e realizar programas de treinamento e de desenvolvimento de habilidades.

Reforçar e ampliar o nível de conhecimentos será essencial para um melhor relacionamento e maior participação de todos, no trabalho e na sociedade.

Estamos na era do Conhecimento: "O conhecimento é a nova forma de Riqueza das Nações”. O aprendizado permanente é indispensável para assegurar crescente competência.

Uma melhor divulgação e um melhor acesso às informações, bem como o aprimoramento da comunicação, têm conduzido a uma interação crescente entre os programas de treinamento, o sistema de gestão e a tecnologia de informação, com maior descentralização e transparência das decisões.

Nessa avalanche de informações dos nossos dias, é determinante ter o discernimento para identificar aquelas que se transformem em conhecimento e, mais ainda, ter acuidade para separar quantidade de conhecimento daquele que realmente represente benefício para a organização e para a sociedade.

A inexistência de fronteiras para a difusão do conhecimento e a mobilidade de acesso a esse conhecimento para todos permitirão que qualquer pessoa obtenha o exigido para seu trabalho. A tecnologia de informação faculta sua disseminação quase instantânea, tornando-o universalmente accessível.

Essas características evidenciam que todas as instituições fundamentadas no conhecimento - empresas, escolas, universidades, hospitais, órgãos públicos - precisam de ser competitivas globalmente, mesmo que atuando local e regionalmente.

*Adaptação da exposição apresentada na solenidade do $126^{\circ}$ aniversário da Escola de Minas, com reflexões sobre as Organizações e sobre o papel da Escola e de todos aqueles que com ela se envolvem ou se relacionam. 
A sabedoria no uso do conhecimento consiste em transformá-lo em benefício para a sociedade.

Esse espírito de cidadania e responsabilidade social tem sido crescente em nossas organizações, caracterizando a aprovação e o respeito da sociedade para algumas de nossas lideranças empresariais e comunitárias.

\section{O papel da Escola de Minas}

A Escola de Minas da Universidade Federal de Ouro Preto precisa, ela também, reforçar esta responsabilidade com uma Educação Integral e resgatar o nível de excelência, respeito, renome e confiança que marcou o "cum mente et malleo" durante tantas décadas, no cenário nacional.

É indispensável credenciar os seus engenheiros para ampliar a sua participação na condução e liderança de grandes projetos e programas de desenvolvimento técnico-científico, econômico e social do País.

O papel da Escola de Minas é, obviamente, o de formar um bom profissional, que saiba responder às necessidades, atuais e futuras, de sua empresa, de nossa sociedade e da Nação.

Para garantir uma posição de vanguarda, ela precisa inovar, oferecer um diferencial, uma vantagem competitiva.
É necessária uma permanente adequação de seus cursos, antecipando-se, para atender às necessidades do mercado, em todas suas dimensões.

O desempenho de qualquer organização (ver figura abaixo) está fundamentado, basicamente, em uma efetiva liderança e em três tipos de conhecimentos de seus integrantes e profissionais: o geral, o técnico e o gerencial.

- O conhecimento geral pode contribuir para um melhor relacionamento e destaque no trabalho e na comunidade, compreendendo o bom domínio de línguas, da comunicação, de informática e boa base cultural e humanista.

- O conhecimento técnico é o específico para o exercício de cada profissão, caracterizado pelo domínio da legislação, de técnicas de engenharia, da mecânica, da medicina, etc.

- O conhecimento gerencial é o que assegura a boa administração dos recursos técnicos, materiais e humanos, com maior produtividade e garantindo a sobrevivência e maior competitividade.

É, portanto, essencial que a Escola exerça uma liderança, com um adequado equilíbrio entre tais tipos de conhecimento e habilidades indispensáveis para uma formação integral; entre

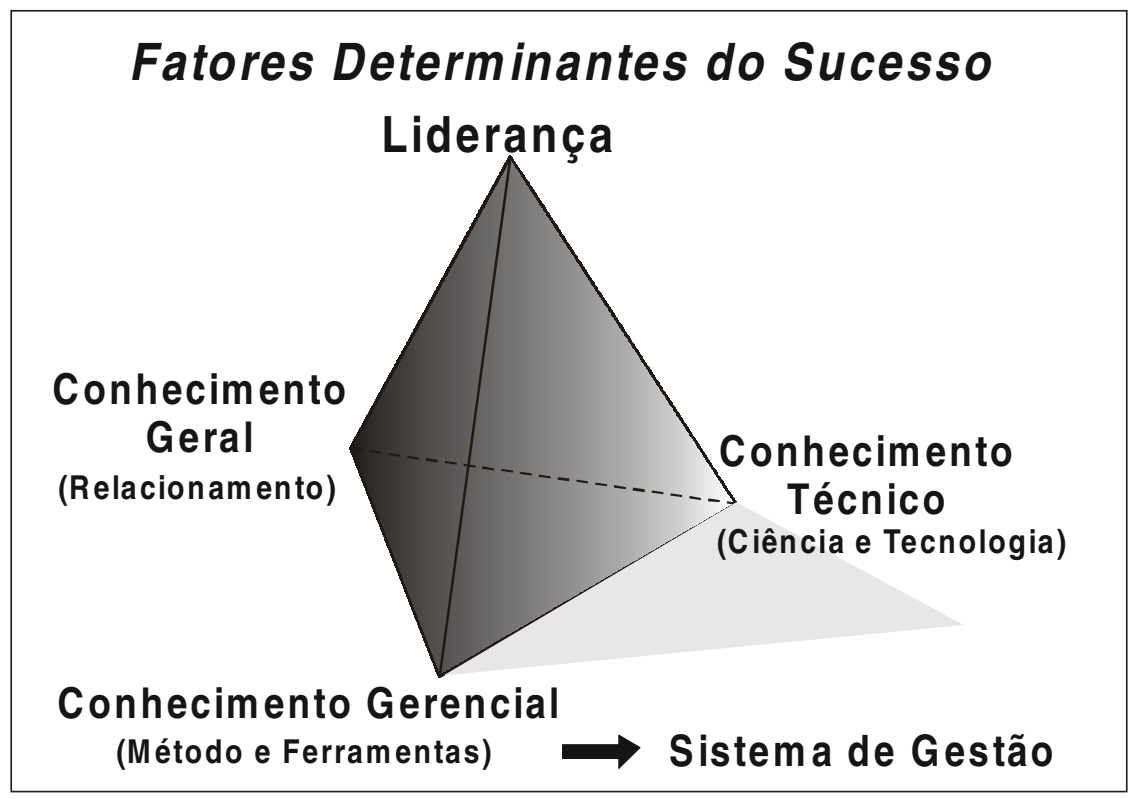

as Ciências e as Humanidades, entre ciência e tecnologia e entre o ensino e a pesquisa.

O papel da Escola de Minas é valorizar o Homem, a ele concedendo sólida formação. É imperativo resgatar o espírito de GORCEIX para propiciar essa formação integral e, na área técnica, a integração entre conhecimento e habilidade/experiência. Essa inspiração em Gorceix intensificará o uso de laboratórios, pesquisas de campo, maior interação com o setor produtivo, permitindo que o adequado uso do conhecimento passe do Saber para o Fazer.

Evitar que o "saudosismo" seja apenas um motivo para frustração. É importante conhecer e estudar o passado para melhor compreender o presente e, principalmente, para prospectar, avaliar tendências e projetar o futuro.

A Escola precisa preparar excelentes profissionais, possibilitando também o despertar de lideranças e o espírito de empreendimento.

Ela precisa formar bons enge-nheiros para o desenvolvimento e bons pesquisadores, para assegurar a INOVAÇÃO.

Com a abertura de nosso mercado, em 1990, as empresas tiveram que, a curto prazo, aumentar a sua produtividade e sua competitividade, para garantir a sobrevivência. Foi a intensificação de um desenvolvimento tecnológico e a conquista, em uma década, de um desenvolvimento gerencial sem precedentes. Torna-se, agora e no futuro próximo, imprescindível estimular e exercitar a INOVAÇÃO, ampliando o número de patentes nacionais, para sustentar o avanço tecnológico, com redução de dependência externa

O papel da Escola é, ainda, promover melhor compreensão do ambiente e do pensamento empresarial, mostrar a importância do método científico, disseminar a responsabilidade social para professores, servidores, alunos e futuros empresários.

É essencial assegurar que o crescimento do conhecimento técnico não represente abandono ou redução do senso humanista; estar sempre alerta para evitar o tecnicismo sem compromisso social. 
Segundo Mahatma Gandhi: "As coisas que podem nos destruir são: política sem princípios, prazer sem consciência, riqueza sem trabalho, conhecimento sem caráter, negócios sem moralidade e ciência sem humanidade."

Não é tarefa fácil, mas exeqüível. Representará mudanças em nós mesmos, com revisão de paradigmas, reforço da vontade e das atitudes de querer servir, em lugar de querer ser importante, diálogos e acertos, respeito e cooperação mútua para que todos sejam vencedores.

As dificuldades existentes, ou que se apresentem, reforçam a importância de que todas as lideranças atuem de forma associativa e convergente.

Todos sairão ganhando e os diplomas aqui obtidos voltarão a ser um indício seguro de competência intelectual e profissional e referência de responsabilidade e credibilidade.

A Escola de Minas, seus profissionais e seus engenheiros interagem e atuam em diversos setores de atividades, que podem ser grupados, de forma esquemática, em três áreas (ver figura ao lado):

- O Setor Produtivo (bens e serviços) como as indústrias, sociedades de projetos, consultorias, etc.

- A Infra-Estrutura Científico-Tecnológica, com o Sistema Educativo, a pós-graduação, a pesquisa, a tecnologia de informação, as entidades de estudos, etc...

- O Governo, em todos os níveis, atuando em todos os setores da economia e, em especial, com órgãos planejadores, de apoio, de coordenação.

Todos essas áreas devem integrar-se com a Sociedade, devendo também ser considerados o crescente universo das organizações não governamentais e os meios de comunicação.

Os órgãos do Governo e os da vertente pública da infra-estrutura científico-tecnológica possuem, ainda, em sua maior parte, uma característica comum: estruturas de maior rigidez, de pouca

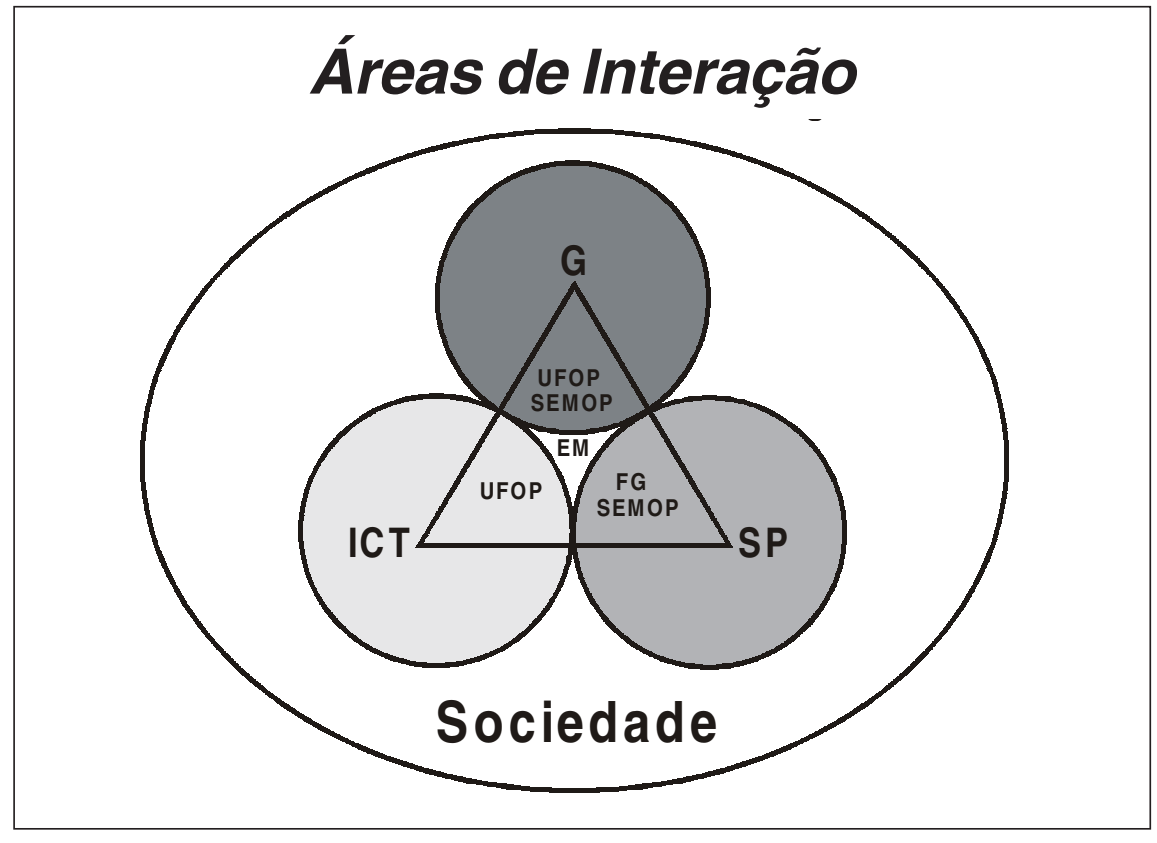

agilidade, com mecanismos e postura de ordem burocrática, baixo compromisso com metas, resultados e prazos, freqüentemente com conflitos entre o aspecto "político" e o "técnico" em muitas de suas atividades.

Para superar tais dificuldades é indispensável que a Escola de Minas tenha RESPONSABILIDADE sobre os RESULTADOS e METAS que tenham sido ditados pela SOCIEDADE - Setor Produtivo, Governo e a própria Universidade - mas, principalmente, conforme princípio básico de um Sistema de Gestão, tenha AUTORIDADE sobre os processos e sobre os meios.

É essencial descentralizar, horizontalizar a gestão e verticalizar o conhecimento como produto, para melhor atender futuras demandas. Em lugar de olhar para dentro e para cima, é essencial olhar para os lados e para fora.

A Universidade deverá cobrar produtividade, qualidade do ensino e da pesquisa e a produção acadêmica, ficando assegurada à Escola de Minas maior autonomia em sua gestão, para os processos didáticos, administrativos e financeiros, mesmo que com referências balizadoras.

A necessidade de maior agilidade nas decisões e no alcance das metas tem provocado crescente atenção do setor público em projetos de modernização da administração, com racionalização de processos e avaliação da estrutura organizacional. É urgente que a Escola avalie sua estrutura, modernize sua gestão, inovando, se necessário.

As incertezas e ansiedades quanto ao futuro da Escola reforçam a urgência de ser efetuada uma Formulação Estratégica, para melhor avaliar cenários, externo e interno, e promover reflexões e diálogos para que se torne mais competitiva e eficiente, juntamente com todos os órgãos e instituições que façam parte de sua cadeia de relacionamento para a formação de competentes profissionais

Essa Formulação Estratégica permitirá projetar cenários e planejar ações para reagir a diversas circunstâncias, favoráveis ou adversas. Mais importante do que prever ou saber o que vai, de fato, acontecer, é estar preparado para saber o que fazer em diferentes cenários. É mais importante maximizar o uso dos pontos fortes do que tentar conciliar conflitos.

O estabelecimento de metas, ações estratégicas e seus planos de ação, mostrará o melhor caminho para otimizar os recursos e o relacionamento da Escola com os órgãos do Governo, da própria Universidade, com o setor produtivo e com a comunidade. 
Seria importante interagir com outras unidades da Universidade, para o desenvolvimento dessas unidades e da própria UFOP; assegurar adequada dose de humanismo e cultura para seus profissionais e alunos, contribuindo também para o desenvolvimento dessas unidades; elas poderiam também contribuir para treinar e transmitir aos professores da Escola a capacidade de fazer o aluno aprender, tão ou mais importante que dispor de um diploma de doutorado.

Um permanente intercâmbio com o setor produtivo é essencial para detectar necessidades futuras para o ensino, para a pesquisa e para o desenvolvimento tecnológico, considerando mesmo peculiaridades setoriais e/ou regionais. Isto permitirá melhor compreensão do ambiente empresarial, por parte de professores/pesquisadores e alunos e mostrará ao profissional da indústria a importância do método científico e da pesquisa.

Nesse relacionamento com o MERCADO, a Escola deverá reforçar a extraordinária oportunidade de contar com a Fundação Gorceix. Estará aumentando a sua flexibilidade, agilidade de decisões, melhorando o acesso e o conhecimento do mercado, a credibilidade, a segurança de cumprimento de prazos, a marca, a mobilidade e o apoio comercial e jurídico.

$\mathrm{Na}$ parte voltada para a busca do conhecimento e desenvolvimento tecnológico e de pesquisas de ponta, a Escola de Minas precisa promover maior intercâmbio com os melhores centros de pesquisa, no País e no exterior, de universidades e de indústrias.

- Convidar empresários, especialistas e técnicos para visitas e conferências na Escola, sobre os diversos setores de atividades.

- Reforçar intercâmbio com órgãos setoriais de federações das indústrias (FIEMG), com associações de classe do setor mineral e estimular atividades similares com apoio às sociedades técnicas dos alunos da Escola.

Nesse campo de atividades, a Escola poderá realizar programas conjuntos ou utilizar também o relacionamento da própria Universidade, da Fundação Gorceix e de seus ex-alunos (SEMOPs $\left.\mathrm{A}^{3} \mathrm{EM}\right)$.

A Escola deverá, ainda, intensificar o relacionamento com a comunidade, sedimentando o senso de responsabilidade social e contribuindo com a Universidade, a qual, como entidade de crítica social, possa intensificar seus projetos que visem ao crescimento social. Será também uma oportunidade para melhor identificar necessidades do mercado.

É imperativo lutar para que se dê prioridade à Educação a fím de melhorar a qualidade do ensino e aprendizagem, desde o ensino básico. Aqueles que costumam dizer que são muitos os recursos ou altas as despesas com a Educação afirmam isto porque, certamente, desconhecem os custos da ignorância ou da baixa capacitação.

O papel reservado à Universidade ganha relevo, menos como uma concentração de estabelecimentos ou departamentos de ensino, e mais como uma instituição responsável por uma formação integral, capaz de gerar, acumular e transmitir conhecimentos e habilidades.

É também essencial que as inovações tecnológicas, com a revolução criada nos meios de comunicação, sejam intensamente aplicadas em benefício da EDUCAÇÃO, para que não se amplie o hiato com a área industrial.

Ouro Preto dispõe das condições para se tornar um Centro de Excelência, em nível mundial, no setor mineral.

É apenas indispensável uma conjunção de lideranças locais.
A Universidade e sua Fundação (FEOP) devem concentrar sua atuação nas demais áreas do conhecimento, considerando que a ESCOLA DE MINAS tem marca, renome, respeito e condições para nuclear e consolidar esse Centro de Excelência, com posição de vanguarda nos cenários nacional e mundial e, assim, também, projetar a própria Universidade.

O alcance desse objetivo deve ser conduzido pelas lideranças dessas Instituições, podendo contar com a colaboração daqueles que "aqui passaram, se formaram e já se foram”, que, por intermédio das SEMOPs, poderão ser mobilizados para tal empreitada.

Tenhamos em mente que "os vencedores sempre encontram as ferramentas adequadas para superar obstáculos”.

Estaremos todos constatando, novamente, que a Escola de Minas estará fazendo de seus profissionais, professores, alunos e ex-alunos os agentes de mudanças para um forte desenvolvimento científico, tecnológico, econômico e social do País e, mais do que isto, tendo decisiva contribuição para a melhoria da qualidade de vida da população.

A preocupação em dar mais atenção ao Homem e à sua formação integral terá resposta.

O exemplo terá desdobramentos e será multiplicado.

Teremos, simultaneamente, profissionais com conhecimentos e experiência e pessoas com atitudes que traduzem valores morais, humanos, com ética, coerência e responsabilidade em seus discursos e suas ações.

Estaremos sustentando, de forma plena e duradoura, o desenvolvimento e o progresso do País, com participação maior e mais respeitada no concerto das nações. Esta é a nossa Missão.

\section{REM a sua revista técnica}

